\title{
Optimal functional outcome measures for assessing treatment for Dupuytren's disease: a systematic review and recommendations for future practice
}

\author{
Catherine Ball $^{1 *}$, Anna L Pratt ${ }^{2}$ and Jagdeep Nanchahal ${ }^{1}$
}

\begin{abstract}
Background: Dupuytren's disease of the hand is a common condition affecting the palmar fascia, resulting in progressive flexion deformities of the digits and hence limitation of hand function. The optimal treatment remains unclear as outcomes studies have used a variety of measures for assessment.

Methods: A literature search was performed for all publications describing surgical treatment, percutaneous needle aponeurotomy or collagenase injection for primary or recurrent Dupuytren's disease where outcomes had been monitored using functional measures.

Results: Ninety-one studies met the inclusion criteria. Twenty-two studies reported outcomes using patient reported outcome measures (PROMs) ranging from validated questionnaires to self-reported measures for return to work and self-rated disability. The Disability of Arm, Shoulder and Hand (DASH) score was the most utilised patientreported function measure $(n=11)$. Patient satisfaction was reported by eighteen studies but no single method was used consistently. Range of movement was the most frequent physical measure and was reported in all 91 studies. However, the methods of measurement and reporting varied, with seventeen different techniques being used. Other physical measures included grip and pinch strength and sensibility, again with variations in measurement protocols. The mean follow-up time ranged from 2 weeks to 17 years.

Conclusions: There is little consistency in the reporting of outcomes for interventions in patients with Dupuytren's disease, making it impossible to compare the efficacy of different treatment modalities. Although there are limitations to the existing generic patient reported outcomes measures, a combination of these together with a disease-specific questionnaire, and physical measures of active and passive individual joint Range of movement (ROM), grip and sensibility using standardised protocols should be used for future outcomes studies. As Dupuytren's disease tends to recur following treatment as well as extend to involve other areas of the hand, follow-up times should be standardised and designed to capture both short and long term outcomes.
\end{abstract}

Keywords: Dupuytren's disease, Hand function, Outcome measures, Systematic review

\footnotetext{
* Correspondence: cathy.ball@kennedy.ox.ac.uk

'Kennedy Institute, University of Oxford, Aspenlea Road, London W6 8LH, UK

Full list of author information is available at the end of the article
} 


\section{Background}

Dupuytren's disease (DD) is a common fibroproliferative disorder of the hand affecting 4-6\% of the population in northern Europe [1]. It is characterized by the progressive thickening and shortening of the palmar fascia, resulting in the formation of cords, flexion deformities of the digits, and hence loss of range of motion, particularly functional extension [2]. DD often restricts a patient's ability to undertake daily activities of living, depending on the location, extent and severity of disease. The deterioration in hand function is the main motivator for patients seeking treatment [3].

DD is progressive, advancing at varying rates, and may occur bilaterally. It can also recur in the same digit following treatment or appear at another site in the hand (disease extension). Furthermore, the effects of recurrence are not uniform and some patients may opt to have further intervention. Therefore, the development of a uniform set of measures to accurately assess functional impairment has proved challenging.

Most patients with early disease, i.e. before the development of digital contractures, are left untreated, although radiation [4] and steroid injections [5] have been used. Currently, the mainstay of treatment for patients with established flexion deformities is surgery in combination with hand therapy. The aim of surgical procedures for DD is to preserve and, if possible, improve hand function. Surgery comprises either the division (fasciotomy) or removal (fasciectomy or dermofasciectomy) of the diseased tissue. Needle fasciotomy divides the cord in a minimally invasive manner. However, recurrence is common, with one study [6] reporting a rate of $84.9 \%$ at 5 years following needle fasciotomy compared with $20.9 \%$ following limited surgical fasciectomy. Discontinuity of the cords may also be achieved enzymatically, with $77 \%$ of metacarpophalangeal joints and $40 \%$ of proximal interphalangeal joints being corrected to within 5 degrees of full extension [7]. However, like needle fasciotomy, recurrence rates are high, affecting $56 \%$ of PIP joints and $27 \%$ of MCP joints at 3 years [8].

\section{The need for a systematic review on outcomes used in Dupuytren's disease}

The optimal treatment in DD remains controversial, in large part due to the lack of evidence based on good quality clinical outcomes studies. Not only is there a paucity of research reporting functional outcomes data for DD but also a lack of consensus on the parameters that should be used. Traditionally, the evaluation of treatment success for DD has largely been determined by clinical examination and physical measures, although improvement in physical measures does not necessarily reflect function [9]. Functional outcome measures specifically assess the consequences of impairment in daily activities. A recent systematic review of efficacy and safety of DD surgery in European patients noted that the commonest outcome measure was improvement in mean joint contracture [10]. However, hand function outcomes were not included in this review. The scarcity of studies reporting functional outcomes following treatment for DD has previously been highlighted [11] and noted in a review of surgical treatments for primary DD [12]. More recent studies have monitored functional outcomes using patient reported outcome measures (PROMs), which have been recognised as an important measure of the effectiveness of care from the patient's perspective [13].

The aim of this review is to identify and determine the relevance and efficacy of outcomes measures used to assess change in hand function following treatment DD by surgery, needle fasciotomy or collagenase injection. This will provide an evidence base to inform the selection of appropriate measures for future research on the management of patients with DD.

\section{Methods}

\section{Search strategy}

The search strategy and search terms were based on a Participants, Intervention, Comparison, Outcomes and Study design (PICOS) [14] (Additional file 1: Table 1). We included studies published over the last 20 years in the English language of adults who had surgery, needle fasciotomy or collagenase injection for primary or recurrent DD where outcomes were monitored using standardised PROMs, functional tests or physical measures as opposed to recording unsubstantiated improvement. Functional outcomes measures reported in randomised and non-randomised controlled clinical trials, prospective and retrospective case series were included. Non-invasive interventions including radiotherapy, steroid injection alone, splinting and skeletal traction were also excluded, as were case studies, conference abstracts and letters. There was no restriction regarding the time that patients were monitored post-intervention.

\section{Search methods for identification of studies}

A literature search was performed in July 2012 using subject heading and free-text terms. Three databases, Ovid Medline, Embase and CINAHL (via EBSCOHost) were searched from 1992 to July 2012. PubMed was also searched from September 2010 - July 2012 to capture electronic publication ahead of print studies not included in Ovid Medline. Searches were limited to studies in English. Search results were imported into an EndNote library and 616 publications were identified for title/abstract review after removal of duplicates.

Two authors (CB, ALP) individually screened the studies using the study eligibility tool to identify studies for inclusion with information gained from the electronic databases (minimum title). Where necessary, consensus 
was achieved by reviewing the full text. Five hundred and twenty five studies were excluded, resulting in 90 articles meeting the inclusion criteria. Following detailed assessment of the included articles, one further publication was identified from their reference lists. The study selection process is summarised in Additional file 2: Figure 1.

\section{Data collection and analysis}

Data on intervention, population and outcomes were collected and tabulated on a Microsoft Excel (Microsoft, Seattle) spreadsheet. Amalgamation of data for statistical analysis was not possible due to the heterogeneity of the studies. Therefore, description of the data is presented to illustrate the variety of functional outcome measures used and the quality of the data. Where available, numerical data are presented as means with range and standard deviation.

\section{Results}

\section{Clinical study design}

Of the 91 included studies, 66 pertained to surgery, 16 to needle fasciotomy and 9 to collagenase injection. All 9 publications reporting the outcomes of collagenase injection were randomised controlled trials or prospective studies. Many studies reporting surgery $(n=29,43.3 \%)$ were retrospective reviews. Eighteen publications reporting outcomes for surgery and 4 needle fasciotomy studies were prospective. In 17 studies (18.7\%) it was not possible to establish whether they were prospective or retrospective in design and were categorised as 'unclear'. The functional outcomes used for each of the three interventions is summarised in Additional file 3: Table 2.

\section{Patient reported outcome measures (PROMs) Measures of function}

Twenty-two studies included patient reported data using function PROMs with 13 using validated region-specific questionnaires: the Disability of Arm, Shoulder and Hand (DASH) $(n=11)$, Quick-DASH $(n=1)$ and the
Patient Evaluation Measure (PEM) $(\mathrm{n}=1)$. Two used the Michigan Hand Outcomes Questionnaire (MHQ) in addition to the DASH. A recently developed diseasespecific questionnaire, Unité Rhumatologique de Affections de la Main scale (URAM), was utilised by one study [15] and 8 used other self-report measures such as return to work or self-rated disability. A further 5 reported the use of function PROMs but did not present the results [16-20]. The use of PROMs is summarised in Figure 1.

The DASH questionnaire [21] was the most frequently used function PROM (11 studies) but only 6 studies presented calculated pre-and post-treatment data [22-27] (Table 1).

The DASH score is calculated using the formula ((sum of $\mathrm{n}$ responses) -1)/nx25), where $\mathrm{n}$ represents the number of completed items, resulting in an aggregate calculated score ranging from 0 to 100 , with a higher score indicating a greater level of disability [21]. Mean pretreatment values ranged from 12.1 (SD 2.9) [23] to 24 (SD 20) [25] and post-treatment from 3.44 (range 0 to 52.5) [28] to 8 (SD 8) [25]. It should be noted that a further two studies presented uncalculated or 'raw' DASH scores evidenced by reporting a score in excess of 100 [29] or interpreting a score of 30 as 'no self-perceived disability' [30] and were excluded as presentation of the data in this way precluded comparison with other studies.

Two studies additionally used the Michigan Hand Questionnaire (MHQ) [23,25]. The MHQ [31] is scored using an algorithm described in the MHQ codebook [32]. Scores can range from 0-100 for each hand, with higher values representing better function, except for pain, where a higher score indicates more pain. Both studies reported significantly improved global MHQ scores compared to pre-operative scores.

One study utilised the Patient Evaluation Measure (PEM) [33]. The PEM is a validated PROM [34] comprising 3 sections combining hand function and satisfaction

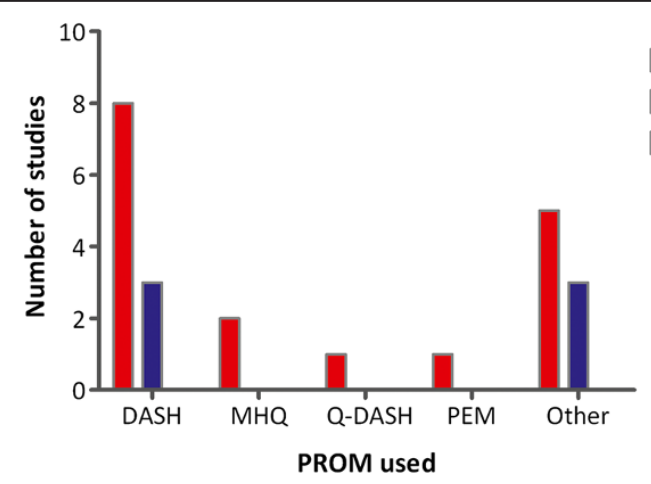

Surgery

Needle apponeurectomy

Collagenase injection

collagenase injection. 


\begin{tabular}{|c|c|c|c|c|}
\hline \multirow[t]{2}{*}{ Author } & \multirow[t]{2}{*}{ No. study subjects } & \multirow[t]{2}{*}{ Assessment schedule (range) } & \multirow{2}{*}{$\begin{array}{l}\text { Pre-op } \\
\text { Mean } \\
\text { (range/ SD) }\end{array}$} & \multirow{2}{*}{$\begin{array}{l}\text { Post-op (final) } \\
\text { Mean (SD) }\end{array}$} \\
\hline & & & & \\
\hline $\begin{array}{l}\text { Engstrand } \\
\text { et al. }\end{array}$ & 60 & Pre and 3 months & $17(7-28)$ & $\begin{array}{l}7(3-12 \\
\text { interquartiles) }\end{array}$ \\
\hline Herweijer* & 46 & Pre and mean 10 (7 to 13 ) months & $12.1(12.9)$ & $6.6(8.8)$ \\
\hline \multirow[t]{2}{*}{$\begin{array}{l}\text { Jerosch- } \\
\text { Herold, }\end{array}$} & \multirow[t]{2}{*}{148} & \multirow[t]{2}{*}{ Pre, 3, 6 and 12 months } & $\begin{array}{l}16.4(15.1) \\
\text { Splint group }\end{array}$ & 7 (14.6) Splint group \\
\hline & & & $\begin{array}{l}15.4 \text { (13.2) No } \\
\text { Splint group }\end{array}$ & $\begin{array}{l}6(9.2) \text { No Splint } \\
\text { group }\end{array}$ \\
\hline $\begin{array}{l}\text { Johnston } \\
\text { et al. * }\end{array}$ & $\begin{array}{l}17 \text { pre-op and } 16 \text { post- } \\
\text { op }\end{array}$ & Pre, 3 and mean of 14 ( 11 to 16 ) months & $24(20)$ & $8(8)$ \\
\hline Skoff, & $\begin{array}{l}30 \text { (cohort of } 10 \text { and } 20 \\
\text { subjects respectively) }\end{array}$ & $\begin{array}{l}\text { Pre and average of } 42 \text { ( } 37 \text { to } 48 \text { ) months for cohort of } 10 \text { subjects. Pre } \\
\text { and average } 32 \text { (range } 24 \text { to 36) months for cohort of } 20 \text { subjects. }\end{array}$ & $\begin{array}{l}37 \text { 'mild } \\
\text { disability' raw } \\
\text { data }\end{array}$ & $\begin{array}{l}30 \text { 'no self-perceived } \\
\text { disability' raw data }\end{array}$ \\
\hline Sobierajska & 35 & Pre, 1 and 3 months & $17.5(14.88)$ & $15.02(15.25)$ \\
\hline \multirow[t]{2}{*}{$\begin{array}{l}\text { Van } \\
\text { Rijssen (a), }\end{array}$} & $50 \mathrm{PNF}$ & Pre, 1,2,3,4 and 5 weeks & $\begin{array}{l}16(14) \text { PNF } \\
\text { group }\end{array}$ & 9 PNF group \\
\hline & $47 \mathrm{LF}$ & & $\begin{array}{l}14(12) L F \\
\text { group }\end{array}$ & 16 LF group \\
\hline Zyluk & 54 & Pre, 3 and 12 months & $\begin{array}{l}54 \text { (30 to } 103) \\
\text { raw data }\end{array}$ & $\begin{array}{l}32(30 \text { to } 104) \text { raw } \\
\text { data }\end{array}$ \\
\hline
\end{tabular}

*Also reported MHQ data in same scheduling.

Number of study subjects and timing of post treatment assessment in studies using DASH and reporting pre- and post-operative data.

with outcome and treatment by asking patients to compare their current versus pre-treatment hand function. The questionnaire is not administered before treatment. The score is calculated by summing the value of the 14 questions in parts 2 and 3 of the PEM and expressed as a percentage of the maximum possible score, with $0 \%$ representing a 'normal' hand. The study assessed hand function and disability in a retrospective postal audit at a mean follow-up of 27 months (SD 8, range not given) and found a correlation with patient assessed deformity. PEM scores ranged from 9 (SD14, range not given) for patients with no deformity to 57 (SD 25, range not given) for severe deformities at both the MCP and PIP joints.

Mean final follow-up times for function PROMs ranged from 3 months [22,35] to 4.5 years [36]. Final follow up times for studies recording pre- and postoperative DASH scores varied between 5 weeks and 48 months.

\section{Patient satisfaction}

Eighteen studies used patient satisfaction as an outcome, with no single method used consistently. These included a visual analogue scale of satisfaction [27,37-39], satisfaction with treatment $[40,41]$, as well as various descriptive responses such as 'very pleased, pleased or disappointed [42], or 'rating of overall clinical success' [39]. Follow-up times ranged from 1 month [43] to median of 4 years (range $1-15$ ) [41].

\section{Tests of function}

Two studies $[44,45]$ utilised the Sollerman hand function test. The Sollerman test comprises 20 unilateral and bilateral hand tasks performed using standardised hand grip patterns intended to reflect normal function in activities of daily living [46]. Performance is graded by the examiner according to the quality of the grip and the time taken to perform each task. The scores range from 0 to 80 , with normative values of 80 for the dominant hand and 77 to 80 for the non-dominant hand. Scores were 72.8 (range not reported) pre-treatment and 78.03 (range not reported) 6 months post-treatment [44]. A second study at the same centre reported scores of 71 (range 62 to 80 ) pre-treatment and 77 (range 66 to 80) 6 months post-treatment [45]. Neither publication reported whether the improvement was statistically significant.

\section{Physical measures \\ ROM}

Range of movement was the most frequent measure and was reported in all 91 studies. However, the methods of recording range of movement varied, with 17 different descriptors. Table 2 summarises the range of motion reporting of all studies. Techniques most commonly used in order of frequency included measurement of flexion contracture $(n=24)$, joint extension deficit $(n=18)$, Tubiana system which grades the DD contracture into 
Table 2 Range of motion reporting: all studies $n=91$ (NB. 29 studies reported more than 1 method)

\begin{tabular}{|c|c|c|}
\hline \multirow{2}{*}{$\begin{array}{l}\text { Range of motion reporting } \\
\text { Description }\end{array}$} & \multicolumn{2}{|l|}{$\mathrm{n}=91$} \\
\hline & Study reference number & Frequency \\
\hline Flexion contracture & {$[16,17,20,30,37,39,48-65]$} & 24 \\
\hline Joint extension deficit & {$[17,18,36,38,45,55,66-77]$} & 18 \\
\hline Active flexion and extension of joint & {$[7,20,25,30,51,53,66,70,78-85]$} & 16 \\
\hline Tubiana Grading system & {$[15,27,43,60,67,71,75,79,86-93]$} & 16 \\
\hline Author defined category & {$[19,33,40,44,47,64,77,78,94-99]$} & 14 \\
\hline Passive extension deficit & {$[6,7,27,43,61,78,85-87,89,90,100]$} & 12 \\
\hline Fixed flexion deformity & {$[94,97,101-104]$} & 6 \\
\hline Total Active Motion & {$[23,24,35,41,66,70]$} & 6 \\
\hline Flexion deformity & {$[99,105-107]$} & 4 \\
\hline Composite flexion & {$[27,86,87]$} & 3 \\
\hline Flexion deficit & {$[27,71]$} & 2 \\
\hline Extension contracture & {$[29,108]$} & 2 \\
\hline Total lack of active extension & {$[26,35]$} & 2 \\
\hline Percentage change & {$[42,101]$} & 2 \\
\hline Total digital extension & {$[22]$} & 1 \\
\hline Total active extension deficit & [109] & 1 \\
\hline Total lack of active flexion & [35] & 1 \\
\hline
\end{tabular}

Additional file 1: Table 1: Search strategy and search terms using PICOS analysis.

one of four stages based on the combined angles of the MCP and PIP joints $(n=16)$, active flexion and extension deficit $(n=16)$ and the use of author defined categories such as 'improved' or graded according to degree of contracture defined by the author $(n=14)$. Twelve other methods were used in 35 studies (Table 2). Follow-up times post treatment ranged from 2 weeks [27] up to 17 years [47].

\section{Grip and Pinch strength}

Measurements of grip strength or pinch grip were presented in 11 studies but only 3 reported pre- and post-intervention data $[23,25,29]$ and 3 gave a descriptor of post-treatment outcomes, for example 'no significant change or deterioration' $[20,48,66]$. Follow-up times ranged from a median of 81 days [66] to a mean of 3.5 years [28].

\section{Sensibility}

Of 11 studies that reported sensibility testing, only one presented pre- and post-operative data [23]. Sensibility was tested using two-point discrimination (2PD) in 6 studies, Semmes Weinstein Monofilaments (SWM) by 1 group and assessment of light touch by another using the fingertip. No collagenase injection studies recorded sensibility. Three studies reported testing sensibility but data were not presented $[16,86,87]$. Follow-up times after treatment ranged from means of 10 months [23] to 4.4 years [105].
Figure 2 summarises the frequency of the various functional outcomes used before and after each type of intervention.

\section{Discussion}

Our review highlights the heterogeneity of outcome measures used for reporting the results of treatments for DD and the challenges faced when attempting to interpret data to determine best practice. Furthermore, many studies reported in insufficient detail how data were

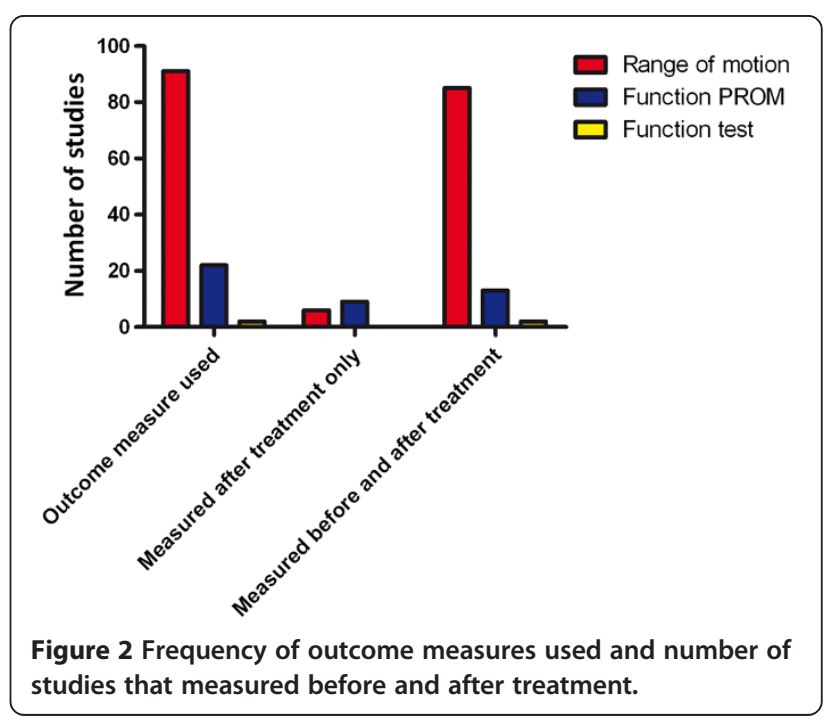


collected. Inconsistencies of outcome measures used and follow-up times have been highlighted previously [12].

The importance of utilising a set of commonly accepted outcome measures that are validated is paramount so that the natural history of the disease as well as treatment success can be monitored at both the patient and population level to enable meaningful comparisons between treatment modalities. Therefore, there is an urgent need for a common consensus regarding the reporting of outcomes data collected in high quality studies.

\section{Patient reported outcome measures}

PROMs, although subjective, are critical measures of treatment efficacy as patient perceived benefit is the ultimate goal of treatment. They should, therefore, supplement data derived from physical measures as they provide the context of the impact on function for the individual. PROMs including functional measures have gained prominence with the current emphasis on patient centred clinical practice. Yet, no publication of collagenase injections used PROMs as an outcome and only 15 publications reporting surgical outcomes used function PROMs. Only one RCT reported outcomes using function PROMs [24].

The DASH questionnaire is a 30-item self-rated region-specific disability and symptom scale outcome measure. It was the most commonly used function outcome measure but may lack the sensitivity to detect significant improvement following surgical or injection treatment for DD due to a 'flooring effect', that is relatively low pre-treatment scores resulting in a reduced potential for improvement [24]. It is difficult to be certain whether this represents a genuine problem as only 6 studies reported pre-treatment DASH scores, although all showed comparatively low values. The normal mean value for the DASH questionnaire reported by the American Academy of Orthopaedic Surgeons [110] was $10.10(+/-14.68 \mathrm{SD})$. All publications reporting preand post-operative data showed a reduction in postoperative scores, indicating an improvement in function compared with pre-operative levels, but this reached significance in only two studies [22,23]. A difference of 15 points is considered to be the minimal clinically important difference (MCID) indicating an improvement [111]. However, the exact figure is controversial and may vary according to the upper limb disorder being considered. No studies achieved a MCID equal to or more than 15 points and only two studies showed a MCID of 10 points [22,25], which may in part be attributed to the relatively low pre-treatment scores. Additionally, caution is advised when applying MCIDs due to difficulties with variation over time of in the patients' perception of their disability [112]. Thus, whilst the evidence for assessing the outcomes of interventions for DD using DASH indicates that it may be useful, further work is necessary to determine the level of change that is considered meaningful.

The Michigan Hand Outcome Questionnaire (MHQ) is a 37-item region-specific outcome measure that includes 6 sub-scales of activities of daily living, hand function, pain, cosmesis, patient satisfaction and overall function [31]. The MHQ has been shown to detect change in function following surgery for DD $[23,25]$ and to correlate with changes in fixed flexion deformity [25]. The MHQ focuses on the hand as compared with the DASH, which assesses entire upper limb function. Furthermore, unlike DASH, the MHQ assesses the functional impact on each hand separately; this may be especially relevant to conditions such as DD that can affect both hands to varying extents. It also includes questions that may be of greater relevance for people with DD. For instance, aesthetics are a construct in the MHQ not included in the DASH and may be relevant for some patients with DD, for example when shaking hands [3] or when presenting the hand with the palm uppermost as when receiving coins.

Whilst the MHQ may appear to be more suitable than the DASH to assess DD outcomes it is lengthy, comprising 74 questions, and may not always be completed. Short versions of the DASH and MHQ have recently become available. The Quick-DASH was used by one study [66] but it is not clear if it is prone to a flooring effect when used for DD. The use of the short MHQ has not yet been reported in outcomes studies for DD. Pain, which is included in both the DASH and MHQ, is seldom reported by people with DD [113] and may reduce the sensitivity of both tools.

The PEM has been shown to be sensitive to change when used for patients with scaphoid fractures or carpal tunnel syndrome [114]. In a study of 100 patients with various conditions affecting the hand [115], including 15 who had DD, patients were able to complete it more rapidly than the DASH or MHQ. A sub-analysis of the results for the patients DD has not been published. Therefore, it is not possible to assess the sensitivity to change in the context of DD.

While there are a number of other hand function questionnaires, these have either been validated for use with specific conditions such as the ABILHAND for rheumatoid arthritis, chronic stroke and systemic sclerosis [116] or do not assess the area affected by DD, such the Patient Rated Wrist Evaluation (PWRE) [117]. Disease-specific hand function questionnaires are generally considered to be desirable as they focus on activities that specifically affect the study population, usually having been developed with patient participation. An example that has been shown to be sufficiently sensitive to 
change is the Boston questionnaire for carpal tunnel syndrome [118]. Recently the Unité Rhumatologique de Affections de la Main scale (URAM) questionnaire [15] and Southampton Dupuytren's Scoring System [119] have been developed as disease specific questionnaires, but have not yet been validated by other investigators.

An alternative approach is to ask individual patients to identify their most restricted activities and when applied to DD, significant improvement in median scores were reported [22].

\section{Patient satisfaction}

Methods used to report patient satisfaction varied, with no single measure used consistently. Studies reported overall satisfaction or satisfaction with surgery but did not explore the relationship with hand function. One study of collagenase injection [78] correlated satisfaction with treatment and improved range of motion at 30 days after the last injection.

\section{Tests of function}

Functional tests are used to provide objective 'measurable' assessment of function. However, critics question their ability to accurately reflect function due to the strict test conditions. Speed of task completion is used to identify change and does not reflect everyday conditions experienced by the patient. The Sollerman was the only functional test used to date in patients with DD. The 2 studies $[44,45]$ using this measure were undertaken in the same centre in the UK, with both reporting change. However, lack of information on reliability, validity and sensitivity for patients with DD, together with lengthy completion time [120] and the need for cumbersome equipment, may limit widespread use.

\section{Physical measures \\ Range of movement}

Range of motion was the most commonly used outcome measure and was reported by every study. It is sensitive to change and benefits from a high inter-rater reliability for patients with DD [121]. However, the relationship between the degree of flexion contracture and loss of function in patients with DD is not necessarily linear $[9,29,122]$, and the amount of change of motion required to translate into a significant functional improvement is unclear and may vary according to the patient and disease severity prior to treatment.

Although ROM was documented in all studies, the reporting was not standardised, making comparison between publications difficult. While studies may appear to be describing the same measure (joint extension deficit, fixed flexion deformity, flexion deformity, flexion deficit, extension contracture), the lack of a standardised measurement protocol means that this cannot be assumed.
For example, many studies did not state how hyperextension was recorded, a common finding at the distal interphalangeal joint or as a compensatory movement at the metacarpophalangeal joint (MCPJ) especially for the little finger in patients with isolated proximal interphalangeal joint (PIPJ) contractures. Fixed deformities should be recorded separately and whether the apparent fixed flexion at the PIPJ can be overcome by flexing the MCPJ should be noted.

The grading system originally described by Tubiana was the joint third most frequently reported measure used for ROM [123]. Clinically it allows easy identification of improvement but not the location of change as it combines the measures of the MCP and PIP joints. Therefore, we suggest that if using the Tubiana grading, it should be supplemented with additional measures to detail the individual joints at which the improvement has been achieved. Similarly, composite ROM measures of finger joints, such as total active motion (TAM), do not permit identification of change at individual joints.

\section{Grip}

Measurements of pinch and grip strength are important aspects of hand function [124] and have been shown to have a strong correlation with disability [125]. However, only 3 of 10 studies that recorded grip or pinch grip strength presented data before and after treatment. Furthermore, assessment of grip and pinch were often not standardised. Grip strength is best measured using a protocol such as that recommended by the American Society of Hand Therapists. A reliable assessment of grip strength is important to capture clinical changes in interventional studies.

\section{Sensibility}

Sensibility testing was mainly used to monitor complications such as inadvertent nerve injury [16,87]. Most authors assumed that participants had normal sensibility before intervention, with only one recording pre-treatment values. Although testing using Semmes Weinstein Monofilaments has been shown to be a superior measure of sensibility assessment following nerve injury than static two point discrimination [126], they were used in only one study.

\section{Limitations of the review}

Excluding articles not published in the English language may have led to potential bias and heterogeneity of studies precluded pooling of data for meta-analysis. The inclusion of low quality studies presenting retrospective data may be viewed as a limitation but an exclusive approach would have resulted in an incomplete picture of current methods used. 


\section{Conclusions}

Studies to date on the outcomes of treatments for patients with DD are heterogeneous and of relatively poor quality. It is critical to achieve a consensus regarding validated outcome measures to monitor disease progression and treatment success in order to enable comparisons between treatment modalities. Subtle deterioration of hand function with functional adaptation in patients with DD over time makes this challenging. Therefore, it is important to use measures that accurately assess global and local disability in a sensitive and specific manner in order to successfully evaluate any change in hand function as a result of intervention. Change in hand function is best assessed by a combination of physical measures and questionnaires [127]. DD can affect multiple digits of the same hand but can also occur bilaterally so comparison with the contralateral hand is not always possible. Inclusion of more than one hand or finger per patient and patient drop out resulting in varying numbers at follow-up represent possible sources of bias.

Based on our findings we recommended the use of a region specific questionnaire such as the MHQ and a validated disease specific PROM like the URAM. A useful addition would be designation of tasks important to each patient and indicating on a linear scale the degree of difficulty before and after treatment. Patient satisfaction should be assessed using a valid and reliable questionnaire such as the Picker questionnaire [128] or PEM. Physical measures of joint ROM, grip and sensibility should be included, with ROM measured before and after treatment using a standardised protocol. We recommend recording measurement of active flexion and extension of each joint and including whether an apparent fixed flexion deformity of the PIPJ can be overcome with passive flexion of the MCPJ. Grip strength should be measured using a validated instrument, such as the Jamar dynamometer according to a standardised protocol. Assessment of sensation using Semmes Weinstein Monofilaments should be used to monitor complications.

Hand function may also be compromised by recurrent disease. Scheduling of follow-up assessments may differ between surgery and other less invasive interventions but final follow-up time should be standardised to capture recurrence and understand how this affects function [129]. Following needle fasciotomy and collagenase injection initial improvement in range of motion and satisfaction may compare favourably with surgery in the short-term but recurrence may compromise function and satisfaction in the long-term.

A comprehensive and consistent approach will enable the development of a robust and reliable evidence base upon which to base best clinical practice for the treatment of patients with Dupuytren's Disease.

\section{Additional files}

Additional file 1: Table 1. Search strategy and Search terms using

PICOS analysis.

Additional file 2: Figure 1. Study selection process flow chart.

Additional file 3: Table 2. Functional outcomes reported by intervention; Collagenase injection, needle fasciotomy and surgery $[3,6,7,15,16,20,22-30,33,35-45,47,48,50-109]$.

Competing interests

The authors declare that they have no competing interests.

\section{Authors' contributions}

CB, ALP performed the literature search and together with JN analysed the data. All wrote the manuscript. All authors read and approved the final manuscript.

\section{Acknowledgements}

We would like to thank K. Bull Librarian, Kennedy Institute for Rheumatology, University of Oxford for her assistance with the literature search as well as James Chan, Liaquat Suleman-Verjee and David Izadi for their critical appraisal of the manuscript.

\section{Author details}

${ }^{1}$ Kennedy Institute, University of Oxford, Aspenlea Road, London W6 8LH, UK. ${ }^{2}$ School of Health Sciences and Social Care, Brunel University, Kingston Lane, Uxbridge UB8 3PH, UK

Received: 24 August 2012 Accepted: 8 March 2013 Published: 10 April 2013

\section{References}

1. Ross DC: Epidemiology of Dupuytren's disease. Hand Clin 1999, 15:53-62. vi.

2. Shih B, Bayat A: Scientific understanding and clinical management of Dupuytren disease. Nat Rev Rheumatol 2010, 6:715-726.

3. Pratt AL, Byrne G: The lived experience of Dupuytren's disease of the hand. J Clin Nurs 2009, 18:1793-1802.

4. Seegenschmiedt MH, Olschewski T, Guntrum F: Radiotherapy optimization in early-stage Dupuytren's contracture: first results of a randomized clinical study. Int J Radiat Oncol Biol Phys 2001, 49:785-798.

5. Ketchum LD, Donahue TK: The injection of nodules of Dupuytren's disease with triamcinolone acetonide. Journal of Hand Surgery 2000, 25(6):1157-1162

6. van Rijssen AL, ter Linden $H$, Werker PM: Five-year results of a randomized clinical trial on treatment in Dupuytren's disease: percutaneous needle fasciotomy versus limited fasciectomy. Plast Reconstr Surg 2012, 129:469-477.

7. Hurst LC, Badalamente MA, Hentz VR, Hotchkiss RN, Kaplan FT, Meals RA, Smith TM, Rodzvilla J: Injectable collagenase clostridium histolyticum for Dupuytren's contracture. N Engl J Med 2009, 361:968-979.

8. Peimer CA, Blazar P, Coleman S, Kaplan FT, Smith T, Tursi JP, Cohen B, Kaufman GJ, Lindau T: Dupuytren Contracture Recurrence Following Treatment with Collagenase Clostridium Histolyticum (CORDLESS Study): 3-Year Data. J Hand Surg Am 2013, 38:12-22.

9. Chen CC, Bode RK: Psychometric validation of the Manual Ability Measure-36 (MAM-36) in patients with neurologic and musculoskeletal disorders. Arch Phys Med Rehabil 2010, 91:414-420.

10. Crean SM, Gerber RA, Le Graverand MPH, Boyd DM, Cappelleri JC: The efficacy and safety of fasciectomy and fasciotomy for Dupuytren's contracture in European patients: a structured review of published studies. J Hand Surg Eur Vol 2011, 36:396-407.

11. Stanbury SJ, Hammert WC: Dupuytren contracture. J Hand Surg Am 2011, 36:2038-2040.

12. Becker GW, Davis TR: The outcome of surgical treatments for primary Dupuytren's disease-a systematic review. J Hand Surg Eur Vol 2010, 35:623-626.

13. Patient Reported Outcome Measurement Group. 2008. http://phi.uhce.ox.ac. uk/home.php. 
14. O'Connor D, Green S, Higgins JPT: Chapter 5: Defining the review question and developing criteria for including studies. In Cochrane Handbook for Systematic Reviews of Interventions version 5.1.0 [updated March 2011]. Edited by Higgins JPT, Green S. The Cochrane Collaboration [http://www.cochrane-handbook.org]

15. Beaudreuil J, Allard A, Zerkak D, Gerber RA, Cappelleri JC, Quintero N, Lasbleiz S, Bernabé B, Orcel P, Bardin T: Unité Rhumatologique des Affections de la Main (URAM) scale: Development and validation of a tool to assess Dupuytren's disease-specific disability. Arthritis Care \& Res (2151464X) 2011, 63:1448-1455.

16. Beard AJ, Trail IA: The 'S' Quattro in severe Dupuytren's contracture. J Hand Surg 1996, 21 B(6):795-796.

17. Coert JH, Nerin JPB, Meek MF: Results of partial fasciectomy for Dupuytren disease in 261 consecutive patients. Ann Plast Surg 2006, 57:13-17.

18. Evans RB, Dell PC, Fiolkowski P: A clinical report of the effect of mechanical stress on functional results after fasciectomy for Dupuytren's contracture. J Hand Ther 2002, 15:331-339.

19. Khan PS, Iqbal S, Zaroo I, Hayat H: Surgical Treatment of Dupuytren's Contracture; Results and Complications of Surgery: Our Experience. $J$ Hand Microsurg 2010, 2:62-66.

20. Ullah AS, Dias JJ, Bhowal B: Does a 'firebreak' full-thickness skin graft prevent recurrence after surgery for Dupuytren's contracture?: a prospective, randomised trial. J Bone Joint Surg Br 2009, 91:374-378.

21. Hudak PL, Amadio PC, Bombardier C: Development of an upper extremity outcome measure: the DASH (disabilities of the arm, shoulder and hand) [corrected]. The Upper Extremity Collaborative Group (UECG). Am J Ind Med 1996, 29:602-608.

22. Engstrand C, Boren L, Liedberg GM: Evaluation of activity limitation and digital extension in Dupuytren's contracture three months after fasciectomy and hand therapy interventions. J Hand Ther 2009, 22:21-26. quiz 27.

23. Herweijer H, Dijkstra PU, Nicolai J-PA, Van der Sluis CK: Postoperative hand therapy in Dupuytren's disease. Disabil Rehabil 2007, 29:1736-1741.

24. Jerosch-Herold C, Shepstone L, Chojnowski AJ, Larson D, Barrett E, Vaughan SP: Night-time splinting after fasciectomy or dermo-fasciectomy for Dupuytren's contracture: A pragmatic, multi-centre, randomised controlled trial. BMC Musculoskelet Disord 2011, 12.

25. Johnston P, Larson D, Clark IM, Chojnowski AJ: Metalloproteinase gene expression correlates with clinical outcome in Dupuytren's disease. $J$ Hand Surg - American Volume 2008, 33:1160-1167.

26. Sobierajska-Rek A, Dobosz M: Early and long-term results following surgery for Dupuytren's disease. Pol Przegl Chir 2010, 82:497-503.

27. van Rijssen AL, Gerbrandy FSJ, Ter Linden H, Klip H, Werker PMN: A comparison of the direct outcomes of percutaneous needle fasciotomy and limited fasciectomy for Dupuytren's disease: a 6-week follow-up study. J Hand Surg - American Volume 2006, 31:717-725.

28. Hogemann A, Wolfhard U, Kendoff D, Board TN, Olivier LC: Results of total aponeurectomy for Dupuytren's contracture in 61 patients: a retrospective clinical study. Arch Orthop Trauma Surg 2009, 129:195-201.

29. Zyluk A, Jagielski W: The effect of the severity of the Dupuytren's contracture on the function of the hand before and after surgery. $J$ Hand Surg Eur Vol 2007, 32:326-329.

30. Skoff HD: The surgical treatment of Dupuytren's contracture: a synthesis of techniques. Plast Reconstr Surg 2004, 113:540-544

31. Chung KC, Pillsbury MS, Walters MR, Hayward RA: Reliability and validity testing of the Michigan Hand Outcomes Questionnaire. J Hand Surg Am 1998, 23:575-587.

32. Institute for Work \& Health: Disabilities of Arms Shoulder Hand, DASH Scoring the DASH. http://www.dash.iwh.on.ca/scoring.

33. Dias JJ, Braybrooke J: Dupuytren's contracture: an audit of the outcomes of surgery. J Hand Surg - British Volume 2006, 31:514-521.

34. Dias JJ, Bhowal B, Wildin CJ, Thompson JR: Assessing the outcome of disorders of the hand. Is the patient evaluation measure reliable, valid, responsive and without bias? J Bone Joint Surg Br 2001, 83:235-240.

35. Glassey N: A study of the effect of night extension splintage on postfasciectomy Dupuytren's patients. Br J Hand Ther 2001, 6:89-94.

36. Van Giffen N, Degreef I, De Smet L: Dupuytren's disease: outcome of the proximal interphalangeal joint in isolated fifth ray involvement. Acta Orthop Belg 2006, 72:671-677.

37. Cheng HS, Hung LK, Tse WL, Ho PC: Needle aponeurotomy for Dupuytren's contracture. J Orthop Surg 2008, 16:88-90.
38. Degreef I, Tejpar S, De Smet L: Improved postoperative outcome of segmental fasciectomy in Dupuytren disease by insertion of an absorbable cellulose implant. J Plast Surg Hand Surg 2011, 45:157-164.

39. Watt AJ, Curtin CM, Hentz VR: Collagenase injection as nonsurgical treatment of Dupuytren's disease: 8-year follow-up. J Hand Surg American Volume 2010, 35:534-539.

40. Hovius SER, Kan HJ, Smit X, Selles RW, Cardoso E, Khouri RK: Extensive percutaneous aponeurotomy and lipografting: a new treatment for Dupuytren disease. Plast Reconstr Surg 2011, 128:221-228.

41. Roush TF, Stern PJ: Results following surgery for recurrent Dupuytren's disease. J Hand Surg - American Volume 2000, 25:291-296.

42. Foucher $\mathrm{G}$, Cornil C, Lenoble E: Open palm technique for Dupuytren's disease. A five-year follow-up. Annales de Chirurgie de la Main et du Membre Superieur 1992, 11:362-366.

43. Beaudreuil J, Lermusiaux J-L, Teyssedou J-P, Lahalle S, Lasbleiz S, Bernabe B, Lellouche H, Orcel P, Bardin T: Multi-needle aponeurotomy for advanced Dupuytren's disease: Preliminary results of safety and efficacy (MNA 1 Study). Joint, Bone, Spine: Revue du Rhumatisme 2011, 78:625-628.

44. Draviaraj KP, Chakrabarti I: Functional outcome after surgery for Dupuytren's contracture: a prospective study. J Hand Surg - American Volume 2004, 29:804-808.

45. Sinha R, Cresswell TR, Mason R, Chakrabarti I: Functional benefit of Dupuytren's surgery. J Hand Surg - British Volume 2002, 27:378-381

46. Sollerman C, Ejeskar A: Sollerman hand function test. A standardised method and its use in tetraplegic patients. Scand J Plast Reconstr Surg Hand Surg 1995, 29:167-176.

47. Abe Y, Rokkaku T, Ofuchi S, Tokunaga S, Takahashi K, Moriya H: Surgery for Dupuytren's disease in Japanese patients and a new preoperative classification. J Hand Surg - British Volume 2004, 29:235-239.

48. Badalamente MA, Hurst LC, Hentz VR: Collagen as a clinical target: nonoperative treatment of Dupuytren's disease. J Hand Surg - American Volume 2002, 27:788-798.

49. Hogemann A, Kendoff D, Wolfhard U, O'Loughlin P, Olivier L: Total vs Partial aponeurectomy for dupuytren's contracture - A literature review. Cent Eur J Med 2010, 5(1):1-5

50. Badalamente MA, Hurst LC: Enzyme injection as nonsurgical treatment of Dupuytren's disease. J Hand Surg - American Volume 2000, 25:629-636.

51. Badalamente MA, Hurst LC: Efficacy and safety of injectable mixed collagenase subtypes in the treatment of Dupuytren's contracture. J Hand Surg - American Volume 2007, 32:767-774.

52. Breed CM, Smith PJ: A comparison of methods of treatment of pip joint contractures in Dupuytren's disease. J Hand Surg - British Volume 1996, 21:246-251.

53. Coleman S, Gilpin D, Tursi J, Kaufman G, Jones N, Cohen B: Multiple concurrent collagenase clostridium histolyticum injections to dupuytren's cords: an exploratory study. BMC Musculoskelet Disord 2012, 13:61

54. Craft RO, Smith AA, Coakley B, Casey WJ 3rd, Rebecca AM, Duncan SFM: Preliminary soft-tissue distraction versus checkrein ligament release after fasciectomy in the treatment of dupuytren proximal interphalangeal joint contractures. Plast Reconstr Surg 2011, 128:1107-1113.

55. Denkler K: Dupuytren's fasciectomies in 60 consecutive digits using lidocaine with epinephrine and no tourniquet. Plast Reconstr Surg 2005, 115:802-810.

56. Gonzalez MH, Sobeski J, Grindel S, Chunprapaph B, Weinzweig N: Dupuytren's disease in African-Americans. $J$ Hand Surg - British Volume 1998, 23:306-307.

57. Mavrogenis AF, Spyridonos SG, Ignatiadis IA, Antonopoulos D, Papagelopoulos PJ: Partial fasciectomy for Dupuytren's contractures. J Surg Orthop Adv 2009, 18:106-110.

58. Meathrel KE, Thoma A: Abductor digiti minimi involvement in Dupuytren's contracture of the small finger. J Hand Surg - American Volume 2004, 29:510-513.

59. Misra A, Jain A, Ghazanfar R, Johnston T, Nanchahal J: Predicting the outcome of surgery for the proximal interphalangeal joint in Dupuytren's disease. J Hand Surg - American Volume 2007, 32:240-245.

60. Moermans JP: Long-term results after segmental aponeurectomy for Dupuytren's disease. J Hand Surg - British Volume 1996, 21:797-800.

61. Pess GM, Pess RM, Pess RA: Results of needle aponeurotomy for Dupuytren contracture in over 1,000 fingers. J Hand Surg Am 2012, 37:651-656. 
62. Sorene ED, Rubinraut-Ophir E, Goodwin DR: Dupuytren's disease in Oriental Jews. J Hand Surg Eur Vol 2007, 32:543-546.

63. Stahl S, Calif E: Dupuytren's palmar contracture in women. Isr Med Assoc J: Imaj 2008, 10:445-447.

64. Uemura T, Kazuki K, Egi T, Yoneda M, Takamatsu K, Nakamura H: Clinical outcomes of primary skin closure with Y-V and Z-plasties for Dupuytren's contracture: use of one-stage skin closure. J Plast Surg Hand Surg 2010, 44:306-310.

65. Weinzweig N, Culver JE, Fleegler EJ: Severe contractures of the proximal interphalangeal joint in Dupuytren's disease: combined fasciectomy with capsuloligamentous release versus fasciectomy alone. Plast Reconstr Surg 1996, 97:560-566. discussion 567

66. Budd HR, Larson D, Chojnowski A, Shepstone L: The QuickDASH score: a patient-reported outcome measure for Dupuytren's surgery. J Hand Ther 2011, 24:15-20. quiz 21.

67. Anwar MU, Al Ghazal SK, Boome RS: Results of surgical treatment of Dupuytren's disease in women: a review of 109 consecutive patients. $J$ Hand Surg - American Volume 2007, 32:1423-1428.

68. Anwar MU, Al Ghazal SK, Boome RS: The lateral digital flap for Dupuytren's fasciectomy at the proximal interphalangeal joint-a study of 84 consecutive patients. J Hand Surg Eur Vol 2009, 34:90-93.

69. Beyermann K, Prommersberger KJ, Jacobs C, Lanz UB: Severe contracture of the proximal interphalangeal joint in Dupuytren's disease: does capsuloligamentous release improve outcome? J Hand Surg - British Volume 2004, 29:240-243.

70. Bulstrode NW, Bisson M, Jemec B, Pratt AL, McGrouther DA, Grobbelaar AO: A prospective randomised clinical trial of the intra-operative use of 5 -fluorouracil on the outcome of dupuytren's disease. J Hand Surg British Volume 2004, 29:18-21.

71. Cools $\mathrm{H}$, Verstreken $\mathrm{J}$ : The open palm technique in the treatment of Dupuytren's disease. Acta Orthop Belg 1994, 60:413-420.

72. Foucher $\mathrm{G}$, Cornil $\mathrm{C}$, Lenoble $\mathrm{E}$, Citron N: A modified open palm technique for Dupuytren's disease. Short and long term results in 54 patients. Int Orthop 1995, 19:285-288.

73. Kemler MA, Houpt $P$, van der Horst CM: A pilot study assessing the effectiveness of postoperative splinting after limited fasciectomy for Dupuytren's disease. J Hand Surg Eur Vol 2012, 37(8):733-737.

74. Kobus K, Wojcicki P, Dydymski T, Wegrzyn M, Hamlawi F: Evaluation of treatment results of patients with Dupuytren's contracture-our clinical experience. Ortop Traumatol Rehabil 2007, 9:134-140.

75. Laurenza F, Gensini A: Rotation of a skin flap from the side of the finger to the volar surface in the treatment of Dupuytren's disease. Ital J Orthop Traumatol 1992, 18:37-41.

76. Rives K, Gelberman R, Smith B, Carney K: Severe contractures of the proximal interphalangeal joint in Dupuytren's disease: results of a prospective trial of operative correction and dynamic extension splinting. J Hand Surg - American Volume 1992, 17:1153-1159.

77. Vigroux JP, Valentin P: A natural history of Dupuytren's contracture treated by surgical fasciectomy: the influence of diathesis (76 hands reviewed at more than 10 years). Ann Chir Main Memb Super 1992, 11:367-374.

78. Witthaut J, Bushmakin AG, Gerber RA, Cappelleri JC, Le Graverand-Gastineau $\mathrm{M}-\mathrm{PH}$ : Determining clinically important changes in range of motion in patients with Dupuytren's Contracture: secondary analysis of the randomized, double-blind, placebo-controlled CORD I study. Clin Drug Investig 2011, 31:791-798.

79. Foucher G, Medina J, Malizos K: Percutaneous needle fasciotomy in Dupuytren disease. Tech Hand Up Extrem Surg 2001, 5(3):161-164.

80. Abe Y, Rokkaku T, Kuniyoshi K, Matsudo T, Yamada T: Clinical results of dermofasciectomy for Dupuytren's disease in Japanese patients. $J$ Hand Surg Eur Vol 2007, 32:407-410.

81. Brotherston TM, Balakrishnan C, Milner RH, Brown HG: Long term follow-up of dermofasciectomy for Dupuytren's contracture. Br J Plast Surg 1994, 47:440-443.

82. Foucher G, Medina J, Navarro R: Percutaneous needle aponeurotomy: complications and results. J Hand Surg - British Volume 2003, 28:427-431

83. Hall PN, Fitzgerald A, Sterne GD, Logan AM: Skin replacement in Dupuytren's disease. J Hand Surg - British Volume 1997, 22:193-197.

84. Midgley R: Use of casting motion to mobilize stiffness to regain digital flexion following Dupuytren's fasciectomy. Hand Therapy 2010, 15:45-51.
85. Sampson SP, Badalamente MA, Hurst LC, Dowd A, Sewell CS, LehmannTorres J, Ferraro M, Semon B: The use of a passive motion machine in the postoperative rehabilitation of Dupuytren's disease. Journal of Hand Surgery 1992, 17(2):333-338.

86. Pereira A, Massada M, Sousa R, Silva C, Trigueiros M, Lemos R: Percutaneous needle fasciotomy in Dupuytren's contracture: is it a viable technique? Acta Orthop Belg 2012, 78:30-34.

87. van Rijssen $A L$, Werker PMN: Percutaneous needle fasciotomy in dupuytren's disease. J Hand Surg - British Volume 2006, 31:498-501.

88. De Maglio A, Timo R, Feliziani G: Dupuytren's disease: recurrence and extension treated by selective aponeurectomy. A clinical review of 124 cases. Chirurgia Degli Organi di Movimento 1996, 81:43-48.

89. Jablecki J, Kaczmarzyk L, Domanasiewicz A, Kaczmarzyk J: Early results of open fasciotomy as a treatment of Dupuytren's disease in elderly patients. [Polish, English]. Polski Przeglad Chirurgiczny 2007, 79(12):1353-1361.

90. Rahr L, Sondergaard P, Bisgaard T, Baad-Hansen T: Percutaneous needle fasciotomy for primary Dupuytren's contracture. J Hand Surg Eur Vol 2011, 36:548-552.

91. Rebelo JS, Ferreira JB, Boleo-Tome J: Dupuytren's disease: Analysis of 110 patients on a long-term follow-up. Eur J Plast Surg 1995, 18(1):32-39.

92. Tripoli M, Cordova A, Moschella F: The "Jacobsen flap" technique: a safe, simple surgical procedure to treat Dupuytren disease of the little finger in advanced stage. Tech Hand Up Extrem Surg 2010, 14:173-177.

93. Tripoli M, Merle M: The "Jacobsen Flap" for the treatment of stages III-IV Dupuytren's disease: a review of 98 cases. J Hand Surg Eur Vol 2008, 33:779-782.

94. Bulstrode NW, Jemec B, Smith PJ: The complications of Dupuytren's contracture surgery. J Hand Surg - American Volume 2005, 30:1021-1025.

95. Duthie RA, Chesney RB: Percutaneous fasciotomy for Dupuytren's contracture. Journal of Hand Surgery 1997, 22 B(4):521-522.

96. Ebskov LB, Boeckstyns ME, Sorensen Al, Soe-Nielsen N: Results after surgery for severe Dupuytren's contracture: does a dynamic extension splint influence outcome? Scand J Plast Reconstr Surg Hand Surg 2000, 34:155-160.

97. Edmunds I, Chien C: A new surgical approach to Dupuytren's disease. $J$ Hand Surg Eur Vol 2011, 36:485-489.

98. Shaw DL, Wise DI, Holms W: Dupuytren's disease treated by palmar fasciectomy and an open palm technique. $J$ Hand Surg - British Volume 1996, 21:484-485.

99. White JW, Kang SN, Nancoo T, Floyd D, Kambhampati SB, McGrouther DA: Management of severe Dupuytren's contracture of the proximal interphalangeal joint with use of a central slip facilitation device. $J$ Hand Surg Eur Vol 2012, 37(8):728-732.

100. Donaldson OW, Pearson D, Reynolds R, Bhatia RK: The association between intraoperative correction of Dupuytren's disease and residual postoperative contracture. J Hand Surg Eur Vol 2010, 35:220-223.

101. Bainbridge C, Gerber RA, Szczypa PP, Smith T, Kushner H, Cohen B, Hellio Le Graverand-Gastineau MP: Efficacy of collagenase in patients who did and did not have previous hand surgery for Dupuytren's contracture. J Plast Surg Hand Surg 2012, 46:177-183.

102. Gilpin D, Coleman S, Hall S, Houston A, Karrasch J, Jones N: Injectable collagenase Clostridium histolyticum: a new nonsurgical treatment for Dupuytren's disease. J Hand Surg - American Volume 2010, 35:2027-2038. e2021.

103. Rajesh KR, Rex C, Mehdi H, Martin C, Fahmy NRM: Severe Dupuytren's contracture of the proximal interphalangeal joint: Treatment by twostage technique. J Hand Surg 2000, 25 B(5):442-444.

104. Ritchie JFS, Venu KM, Pillai K, Yanni DH: Proximal interphalangeal joint release in Dupuytren's disease of the little finger. $J$ Hand Surg - British Volume 2004, 29:15-17.

105. Roy N, Sharma D, Mirza AH, Fahmy N: Fasciectomy and conservative full thickness skin grafting in Dupuytren's contracture. The fish technique. Acta Orthop Belg 2006, 72:678-682.

106. Citron N, Hearnden A: Skin tension in the aetiology of Dupuytren's disease; a prospective trial. J Hand Surg - British Volume 2003, 28:528-530

107. Walton MJ, Pearson D, Clark DA, Bhatia RK: The prognosis of fasciectomy for abductor digiti minimi and pretendinous cords in Dupuytren's disease of the little finger. Hand Surg 2009, 14:89-92.

108. Ekerot $L$ : The distally-based dorsal hand flap for resurfacing skin defects in Dupuytren's contracture. J Hand Surg - British Volume 1995, 20:111-114.

109. McMillan C, Binhammer P: Steroid injection and needle aponeurotomy for dupuytren contracture: a randomized, controlled study. J Hand Surg Am 2012, 37:1307-1312. 
110. Hunsaker FG, Cioffi DA, Amadio PC, Wright JG, Caughlin B: The American academy of orthopaedic surgeons outcomes instruments: normative values from the general population. J Bone Joint Surg Am 2002, 84-A:208-215.

111. Beaton DE, Davis AM, Hudak PL, McConnell S: The DASH (Disabilities of the Arm, Shoulder and Hand) Outcome Measure: What do we know about it now? Br J Hand Ther 2001, 6:109-118.

112. Cook CE: Clinimetrics Corner: The Minimal Clinically Important Change Score (MCID): A Necessary Pretense. J Man Manip Ther 2008, 16:E82-E83.

113. von Campe A, Mende K, Omaren H, Meuli-Simmen C: Painful nodules and cords in Dupuytren disease. J Hand Surg Am 2012, 37A:1313-1318.

114. Hobby JL, Watts C, Elliot D: Validity and responsiveness of the patient evaluation measure as an outcome measure for carpal tunnel syndrome. $J$ Hand Surg Br 2005, 30:350-354.

115. Dias JJ, Rajan RA, Thompson JR: Which questionnaire is best? The reliability, validity and ease of use of the patient evaluation measure, the disabilities of the arm, shoulder and hand and the Michigan hand outcome measure. J Hand Surg Eur Vol 2008, 33(1):9-17.

116. Durez P, Fraselle V, Houssiau F, Thonnard JL, Nielens H, Penta M: Validation of the ABILHAND questionnaire as a measure of manual ability in patients with rheumatoid arthritis. Ann Rheum Dis 2007, 66:1098-1105.

117. MacDermid JC, Turgeon T, Richards RS, Beadle M, Roth JH: Patient rating of wrist pain and disability: a reliable and valid measurement tool. $J$ Orthop Trauma 1998, 12:577-586.

118. Levine DW, Simmons BP, Koris MJ, Daltroy LH, Hohl GG, Fossel AH, Katz JN A self-administered questionnaire for the assessment of severity of symptoms and functional status in carpal tunnel syndrome. J Bone Joint Surg Am 1993, 75:1585-1592.

119. Mohan A, Vadher J, Ismail H, Warwick D: The Southampton Dupuytren's Scoring Scheme [abstract]. J Hand Surg Eur Vol 2011, 36E Suppl. 1:562.

120. Schoneveld K, Wittink $H$, Takken T: Clinimetric evaluation of measurement tools used in hand therapy to assess activity and participation. J Hand Ther 2009, 22:221-235. quiz 236.

121. Engstrand C, Krevers B, Kvist J: Interrater reliability in finger joint goniometer measurement in Dupuytren's disease. Am J Occup Ther 2012, 66:98-103.

122. Jerosch-Herold C, Shepstone L, Chojnowski A, Larson D: Severity of contracture and self-reported disability in patients with Dupuytren's contracture referred for surgery. J Hand Ther 2011, 24:6-10. quiz 11.

123. Tubiana R: Dupuytren's disease of the radial side of the hand. Hand Clin 1999, 15(1):149-159.

124. Fowler NK, Nicol AC: Functional and biomechanical assessment of the normal and rheumatoid hand. Clin Biomech (Bristol, Avon) 2001, 16:660-666

125. Bodur H, Yilmaz O, Keskin D: Hand disability and related variables in patients with rheumatoid arthritis. Rheumatol Int 2006, 26:541-544.

126. Jerosch-Herold C: Assessment of sensibility after nerve injury and repair: a systematic review of evidence for validity, reliability and responsiveness of tests. J Hand Surg Br 2005, 30:252-264.

127. Pap G, Angst F, Herren D, Schwyzer HK, Simmen BR: Evaluation of wrist and hand handicap and postoperative outcome in rheumatoid arthritis. Hand Clin 2003, 19:471-481.

128. Picker Institute Europe: http://www.pickereurope.org/

129. Knobloch K, Kuhn M, Sorg H, Vogt PM: German version of the Unite Rhumatologique des Affections de la Main (URAM) scale in Dupuytren's disease: the need for a uniform definition of recurrence. Comment on the article by Beaudreuil et al. Arthritis Care Res (Hoboken) 2012, 64:793. author reply 794

doi:10.1186/1471-2474-14-131

Cite this article as: Ball et al:: Optimal functional outcome measures for assessing treatment for Dupuytren's disease:

a systematic review and recommendations for future practice. $B M C$

Musculoskeletal Disorders 2013 14:131.

\section{Submit your next manuscript to BioMed Central and take full advantage of:}

- Convenient online submission

- Thorough peer review

- No space constraints or color figure charges

- Immediate publication on acceptance

- Inclusion in PubMed, CAS, Scopus and Google Scholar

- Research which is freely available for redistribution

Submit your manuscript at www.biomedcentral.com/submit
Biomed Central 